\title{
Energy Usage Optimization in Zero Energy Building to Reduce Dependency on Conventional Sources
}

\author{
Rohit Malviya \\ M.Tech Scholar \\ Department of Energy Technology \\ TRUBA Institute of Engineering and Information Technology, \\ Bhopal (M.P.), India \\ rohitmalviya630@gmail.com
}

\author{
Shravan Vishwakarma \\ Asst Professor \\ Department of Energy Technology \\ TRUBA Institute of Engineering and Information Technology, \\ Bhopal (M.P.), India \\ shravanmits@gmail.com
}

\begin{abstract}
As Net-zero energy buildings (NZEBs) have been proposed as a viable method for reducing building energy utilization and pollutant emissions. To achieve the desired performing goal, the layouts and capabilities of the integrated renewable energy systems in NZEBs should be carefully chosen. The persistent rise in global energy demand as a result of industrial advancement and population expansion is presently a massive source of concern. The goal of this project is to develop an ideal design technique for a zero-energy building that takes into account the building's energy output and usage. Solar power production was determined to be the most significant element.
\end{abstract}

Keywords: Zero Energy Building, Net-zero Energy Buildings, Renewable Sources, Energy Optimization.

\section{I.INTRODUCTION}

In "A Net Zero Energy Building (NZEB) is a domestic or commercial structure with greatly decreased energy demands as a result of productivity gains, allowing energy demands to be managed with sustainable technology." The investigators discovered, meanwhile, that the "absolute zero energy structure" can be expressed in a variety of ways, depending on the component and the norms. It's critical to initiate with electricity utilization and minimize energy losses through energy-saving initiatives, such as lighting, ventilation, passive solar energy, elevated appliances, thermal comfort, passive cooling, and so on, before turning to green electricity to confront building energy demands.

The interactions that exist among energy efficiency and on-site solar power generation in addition to attain a net energy value of zero. The conclusions are dependent on the development of the building's comprehensive solar energy system as well as the outcomes of two previous well-known field studies. The goal of this research is to show that energy conservation and sustainable energy generation are inextricably linked, and that a lack of one or the other has a catastrophic impact on the capability to achieve a net-zero energy goal.
Net Zero Site Energy, which equates generated renewable energy with utilized energy, looks to become the most apparent. All energy is created and ingested onsite, that is, inside the building's system boundaries, according to this description.

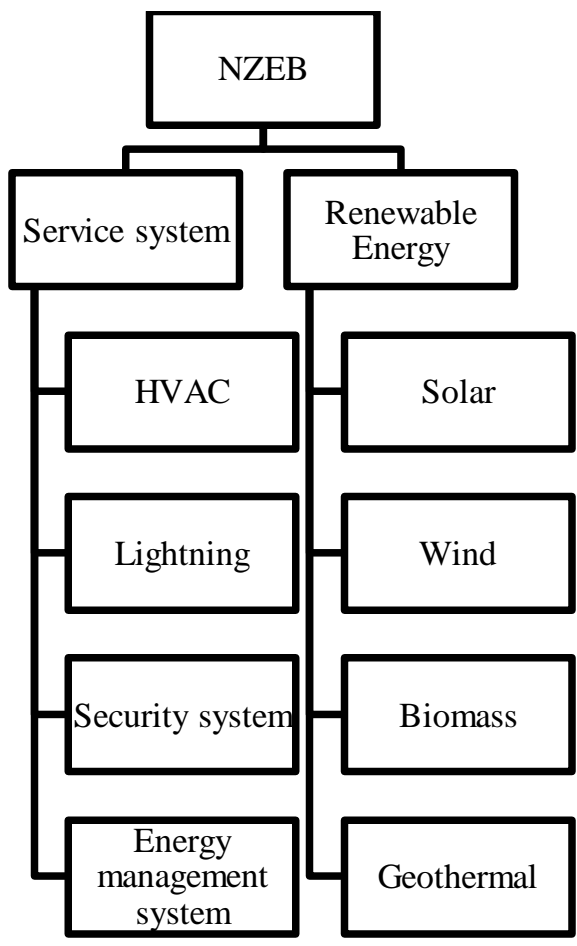

Fig. 1 Design elements for NZEB

Buildings with a great passive design, such as optimum orientation, a high thermal envelope, strong tightness, and well designed shade for windows, have lower thermal and electrical loads.

The main motive of such systems is to efficiently provide a pleasant and indoor environment for the people who live there. Several energy sources, such as natural gas or electricity, will 
inevitably be required to power BSSs. As a result, the REP system must be implemented in order to reduce energy use. If adequate energy potential could be developed, a NZEB could be conceivable with electricity and thermal output from renewable energy sources. Because more and more NZEBs elect to utilize several embedded systems, such as bio-gas CCHP (combined cooling, heating, and power), photovoltaic the term "BES (building energy system)" often implies to the conjunction of BSS and REP system.

As an optimization approach for automating the process of determining the appropriate blend of actions for reducing building energy consumption while meeting the nZEB goals. The research was carried out using a MATLAB Simulink model for both optimization and non-optimization circumstances.

The emphasis in the development of the NZEB was on the priority for energy conservation and the defined doctrine: "Demand first, then supply," which indicates that while attempting to attain a zero energy balance in a building, demand must come first.

Several individuals believe that when it comes to installing a renewable energy system on their property, the choice is between wind turbines and solar panels. If you live in a sunny area, solar panels on your roof are likely to be your first choice. If you live in a location with frequent long, overcast days and strong winds, you should seriously consider purchasing a modest household wind turbine. When you choose among wind and solar, you restrict the quantity of energy your home can generate.

\section{LITERATURE REVIEW}

]Xian $\mathrm{Li}$ et al. [1].According to the report, net zero energy buildings are critical in the decarburization of prospective cities, as dwellings account for 30-40\% of total energy use. Sun energy systems and thermally insulating solar glass have been used to create electricity while minimising heat loss in a net-zero energy residential structure with a commercialized perspective. Evolving and parametric simulation models were generated and evaluated employing experimental findings or standard assessment reports utilising the TRNSYS framework.

ParaschivSpiru et al. [2]. In a temperate region with warm summers and freezing winters, the yearly efficacy of the SAHS incorporation into the building envelope was investigated. Ultimately, the suggested SAHS system was compared against a natural gas boiler system for warming. When state subsidies range from $0 \%$ to $50 \%$, the simple payback period of SAHS investment 11 is between 14 and 5 years, according to the findings of the financial assessment. The SAHS suggested here is economically feasible given the weather situations and building geographical orientation considered, and system installation is a good way to reduce building energy consumption by utilising renewable energy sources.
Li, Xian et al. [3] highlighted that because buildings account for $30-40 \%$ of overall energy use, net zero energy buildings are critical to the carbon reduction of emerging cities. Sun energy systems and thermally laminated solar glass have been used to create electricity while minimising heat loss in a net-zero energy residential structure with a commercialized approach. Evolving and parametric simulation models were generated and evaluated employing experimental data or standard test reports utilising the TRNSYS framework.

A multi-criterion determination methodology depending on energy and economic criteria was created to assess system efficiency and discover the optimum beneficial energy system layout in the zero net energy domestic dwelling. There are twelve different systems.Several scenarios were compared, involving a solar glass system with customized heat control. solar thermal glass and solar thermal glass, insulator, hybrid systems with solar PV, solar thermal glass and solar thermal glass, Hybrid systems integrating sun thermal glass and solar thermal glass are also available.

Wu, Wei and Skye [4] For a domestic NZEB, researchers looked into the energy, convenience, and economic efficiency of commercially accessible HVAC technology. For the NZEB in the humid climate zone, an experimentally authenticated model was utilised to analyse ventilation, dehumidification, and heat pump possibilities. A heat restoration fan (HRV) and an energy recovery fan (ERV) diminished HVAC energy by 13.5 percent and 17.4 percent, respectively, and building energy by 7.5 percent and 9.7 percent, when tried to compare to non mechanical ventilation. In terms of thermal convenience, there was no substantial distinction among such ventilation alternatives.Installation pricing data and two energy pricing patterns were used to assess the feasibility of each HVAC arrangement. The biggest energy savings and comfort were provided by GSHPs with ERV and specialized dehumidification, but they were also the most expensive. With a dedicated ASHP . Dehumidification and ERV (or HRV) allowed for a quick rehabilitation.

Steven J \&amp; Lewis et al. [5] examined what that would require to accomplish energy system decarbonization. Aviation, long-distance transportation, steel and cement manufacturing, and the provision of a stable electricity supply are among the most complex aspects of the energy system to decarbonize. Present technologies and approaches show potential, but achieving low emissions requires the unification of now-separate energy sectors and industrial operations. In order to stabilise worldwide mean temperature, net $\mathrm{CO} 2$ emissions from human actions must approach zero. This includes not only energy 
services and industrial output, but also land usage and agriculture.Exhilarating and generating electricity from varying renewable energy sources (such as wind and solar) and dispatchable ("on-demand") nonrenewable sources (such as nuclear energy and fossil fuels with carbon capture and storage) could make decarbonizing energy services like light-duty transportation, heating, cooling, and lighting relatively simple. Other energy services, however, that are critical to contemporary civilization, produce emissions that will be more challenging to completely eradicate.

Young Tae \&amp; Kim et al. [6 ].In various temperature circumstances, the impact of electrical and optical variables of building incorporated photovoltaic (BIPV) windows with a semi-transparent solar cell on the whole energy efficiency of a typical mid-sized commercial building were investigated. We constructed semi-transparent amorphous silicon $(\mathrm{a}-\mathrm{Si}: \mathrm{H})$ solar cells in varied situations and analysed optical properties of the cells in parallel to energy conversion effectiveness to precisely measure the thermo-optical efficacy of the BIPV windows.

S. \&amp; Wang et al. [7]The NZEB (Net Zero Energy Building) is viewed as a comprehensive remedy to the challenges of energy conservation, environmental conservation, and $\mathrm{CO} 2$ emission mitigation in the building sector, according to the company. With enough electricity, NZEB might be possible.If sufficient renewable energy could be employed, it would be possible to generate adequate electricity. In addition, there are a variety of technical constructions. For prospective uses in the NZEB, renewable energy technologies have been developed. a thorough examination

Ayman \&amp; Hasanet al. [8]The four metrics of primary energy (PE), energy from the site, $\mathrm{CO} 2$ emissions, and power were used to analyse the attainment of four net zero energy balances (NZEB), NZEB-PE, NZEB location, NZEB emissions, and NZEB costs. Weighting variables relying on Finnish and international benchmarks were used to calculate expenses. Five conventional energy systems are examined, as well as seven biomass-based off-grid and block-type power plants (CHPs). These systems are linked to a single-family home in Helsinki, Finland, that has two 14 levels of energy reliability: a conventional house and a passive house, both of which have been simulated using the Trnsys programme.

Li, Danny H.W et al. [10] ZEB is a large source of total energy and $\mathrm{CO} 2$ emissions in the globe, and it plays a vital role in the formation of sustainable advancement initiatives, according to the report. In recent years, interest in Zero Energy Buildings (ZEBs) has grown. Various nations have embraced or are contemplating adopting ZEBs as future energy targets for buildings to address issues such as energy exhaustion and environmental deterioration.

Petros J. Axaopoulos et al. [11] The effectiveness of commercially available $\mathrm{PV} / \mathrm{T}$ systems for electricity and residential hot water generation is being tested for usage in three European nations, each amid completely distinct meteorological and economic circumstances. Economic spider graphics are used to show how legislation and fuel costs influence the utility of such systems, and valuable conclusions about how to evaluate their energetic effectiveness are made.

\section{METHPDOLOGY}

The definition of a building form that may significantly minimize the load on the building by minimizing seasonal heating/cooling requirements based on the $\mathrm{S} / \mathrm{V}$ of the building is the first necessary aspect of zero-energy building design. It has become far more significant than before. Previously, no solar power generation system was established because solar electricity was not available. The capability of renewable energy installations is defined by the renewable energy sources that can be implemented based on the structure's form The second factor is to position the structure in such a way that it consumes as little energy as possible.as much solar power is feasible

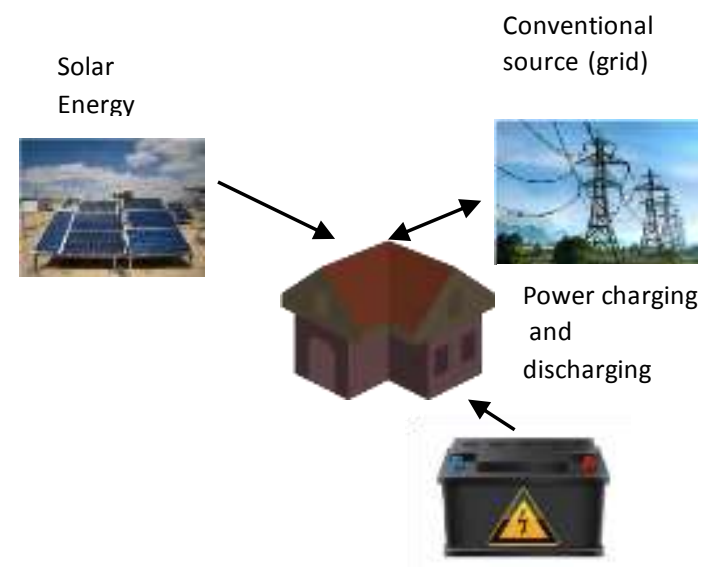

Fig. 2 Energy Exchange in building with renewable resources, battery, and Conventional Sources

The employment of a renewable energy source (solar energy) in a modelled building of the current study, as well as a method of electrical energy exchange with the network and electrical storage (battery), the sun and wind energies are ongoing inputs of electric current into the building. Electrical energy, unlike 
thermal energy, does not have a simple storage capability when it is generated. After the electricity is generated and transformed to a storable state, the battery is employed for this function. In this study, the generated electricity is first preserved using power generators attached to a battery (after the building's electrical energy is supplied), and then, if the battery is fully charged,

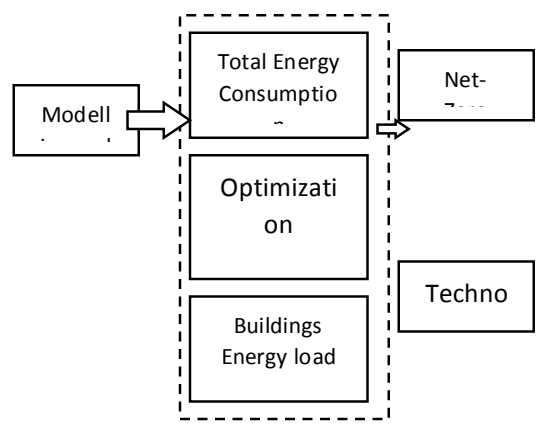

Fig. 3 Proposed Problem-Solving Strategy

In this study, the obtained electricity is first preserved using power generators attached to a battery (after the building's electrical energy is supplied), and then the excess 24 electricity is delivered to the grid if the battery is fully charged. When the building is under a high energy demand, it is also feasible that the conserved electricity is first obtained from the battery, and then the electricity is obtained from the worldwide network when the battery is fully exhausted.

In the following steps, solar energy is added to the existing energy resources of the building and results of their impact on the building are investigated. The crucial poing is that in solving the present problem using optimization problem to total cost of conventional electricity as much as possible.

$$
C_{\text {overall }}=\min \sum_{m=0}^{\mathrm{n}} C_{\text {grid }}(\mathrm{m}) \cdot \mathrm{E}_{\text {grid }}(\mathrm{m})
$$

\section{Gray Wolf Optimization}

GWO is inspired by the hierarchy and hunting behavior of gray wolf populations. The algorithm achieves optimization by mathematically simulating the tracking, surrounding, hunting and attacking the process of gray wolf populations. The gray wolf hunting process involves three steps: social hierarchy stratification, encircling the prey and attacking the prey.

Encircling the Prey Gray wolves encircle prey during the hunt; in order to mathematically model encircling behavior, the following equations are used:

$$
\begin{gathered}
\mathrm{X}(\mathrm{t}+1)=\mathrm{X}_{\mathrm{p}}(\mathrm{t})-\mathrm{A} \cdot\left|\mathrm{C} \cdot \mathrm{X}_{\mathrm{p}}(\mathrm{t})-\mathrm{X}(\mathrm{t})\right| \\
\mathrm{A}=2 \mathrm{a} \cdot \mathrm{r}_{1}-\mathrm{a} \\
\mathrm{C}=2 \cdot \mathrm{r}_{2} \\
a=2-2 \frac{\mathrm{t}}{\text { max_iter }}
\end{gathered}
$$

Attacking the Prey: Gray wolves have the ability to recognize the location of potential prey, and the search process is mainly carried out by the guidance of $\alpha, \beta, \delta$ wolves. In each iteration, the best three wolves $(\alpha, \beta, \delta)$ in the current population are retained, and then the positions of other search agents are updated according to their position information.

\section{RESULTS AND DISCUSSIONS}

The proposed methodology is simulated using MATLAB platform to carry out calculations to obtain the power output in the Zero Energy Buildings. The program automatically calculates the load generated and energy required from solar panels, battery and grid system. Simulation graphs and result analysis are illustrated below.

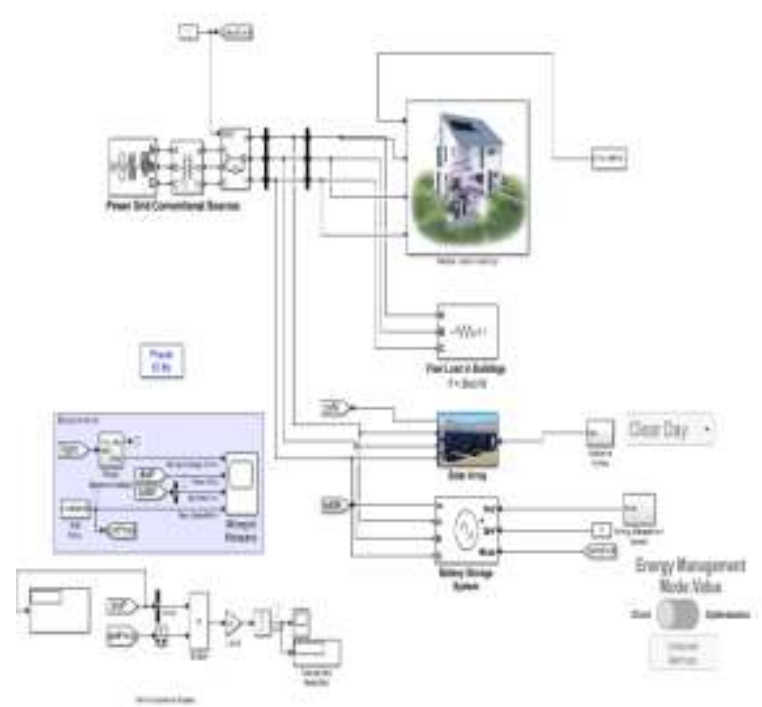

Fig 4. Proposed Modeling of Energy Optimization in ZEB

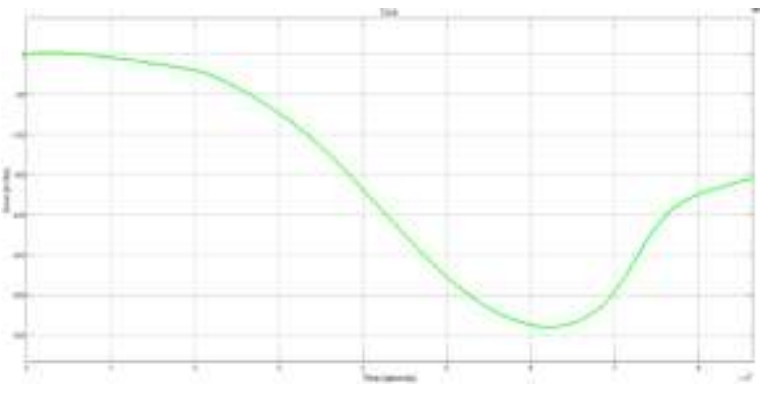

Fig 5. Energy Utilization Cost Estimation 
The above shown graph depicts that as the time goes on cost estimation of energy usage initially reduces and then after a certain time it start increasing. The graph is nonlinear but not chaotic, it is fluctuating with the time it means that is reduces then increases then continues with time.

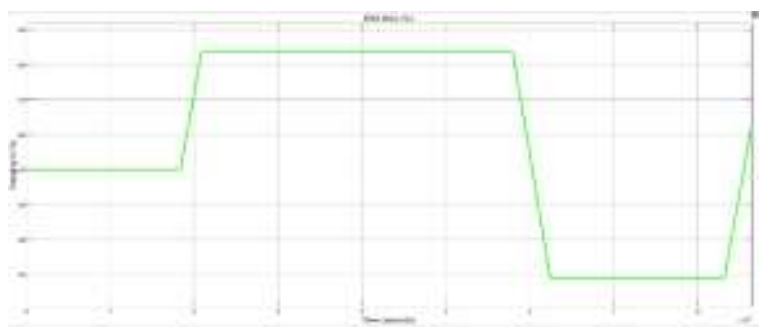

Fig 6. Battery Charging and Discharging State

The battery charging and discharging state graph depicts that once the system is charged then it will be available for some time duration and then it start getting discharge as the energy of the system utilizes. As the system get discharged it have to be charge again but during the process of charging and discharging for some time duration it will remain constant.

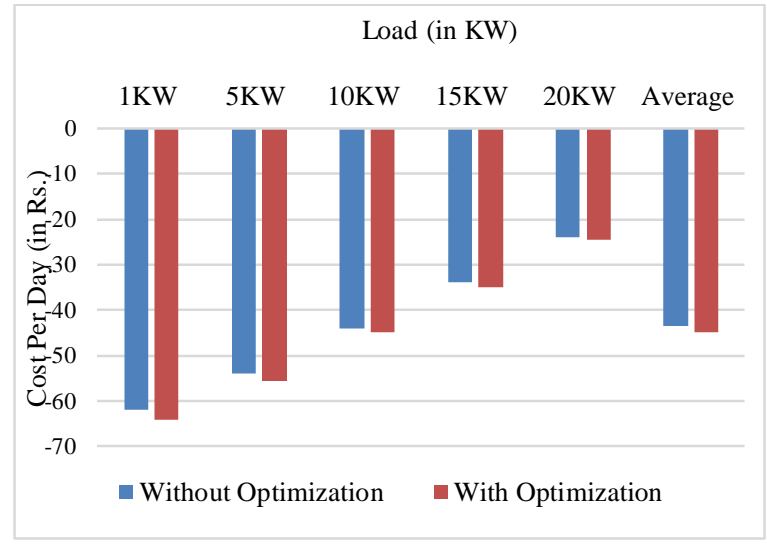

Fig 7. Cost Per Day for Fixed Load Analysis on Cloudy Day

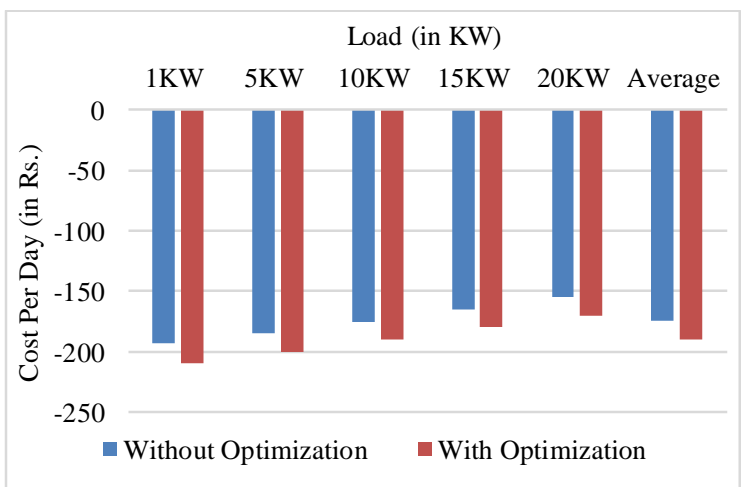

Fig 8. Cost Per Day for Fixed Load Analysis on Clear Sunny Day

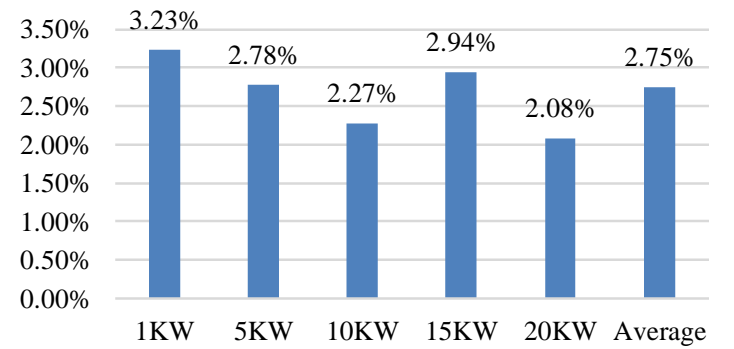

Fig 9. Improvement in Energy Supply to Grid Due to Optimization under fixed load

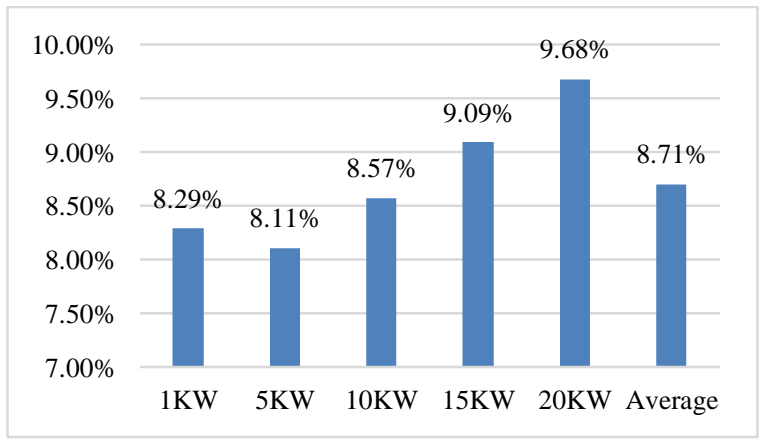

Fig 10. Improvement in Energy Supply to Grid Due to Optimization under variable load

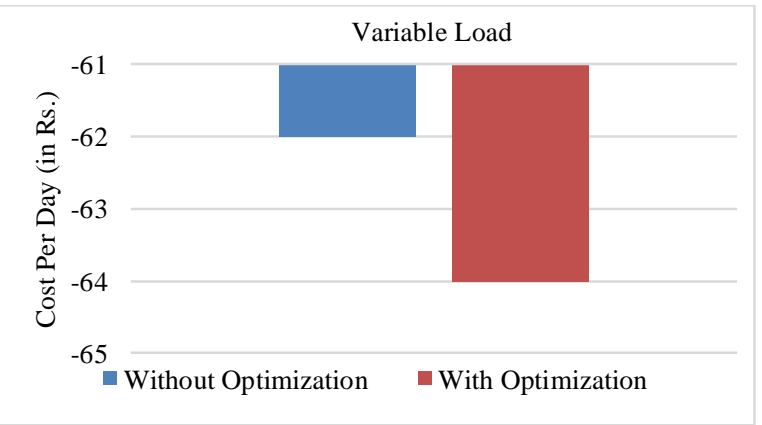

Fig 11. Cost Per Day for Variable Load Analysis on Cloudy Day

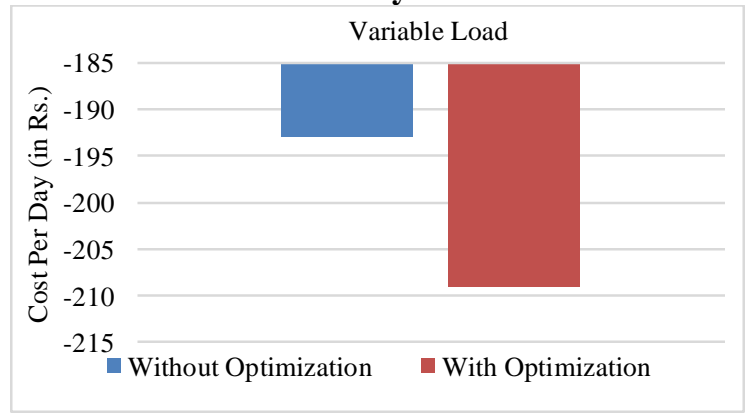

Fig 12. Cost Per Day for Variable Load Analysis on Clear Sunny Day 


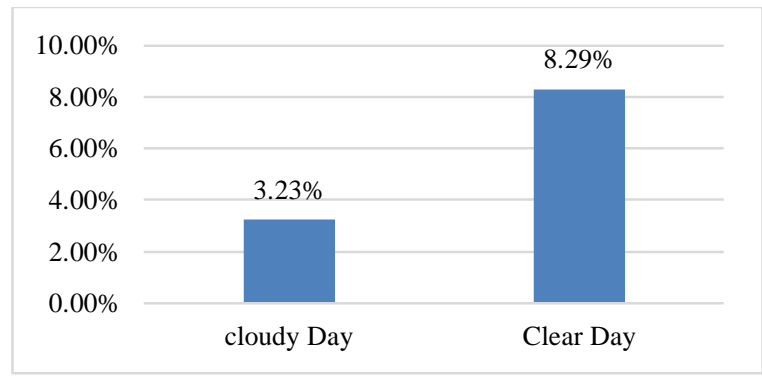

Fig 13. Improvement in Energy Supply to Grid Due to

\section{Optimization under Variable Load}

The graph shown above describes that the improvement in energy supply to the grid is maximum on clear day as compared to the improvement of energy supply to the grid in cloudy day. The improved value on cloudy day is $3.23 \%$ whereas the improved value on clear day is $8.29 \%$.

\section{CONCLUSION}

As enhancing the energy management is undergoing significant modifications at the moment. The inclusion of net zero energy as a long-term aim for new buildings in most advanced nations is a crucial component in this. To accomplish this, much study is required to gather information and put it into practice. Household building energy usage has risen dramatically in previous years, posing a hurdle for zero-energy residential construction systems (ZERB), which aim to considerably diminish household building energy intake. We provide the fundamental concept philosophy of ZERB in this paper, which is predicated on energy optimization and a techno-economic evaluation of the systems' energy requirement. The resulting ideal method enhances energy usage from conventional sources greatly. The model was created using both optimization and non-optimization methods.

\section{REFERENCES}

[1] XianLi, AlexanderLin "Energetic and economic evaluation of hybrid solar energy systems in a residential net-zero energy building" Applied Energy, Volume 254, 15 November 2019, 113709.

[2] ParaschivSpiru, Nicoleta Bărbuță-Mişu "Technical and economic analysis of a solar air heating system integration in a residential building wall to increase energy efficiency by solar heat gain and thermal insulation", December 2020, Energy Reports, DOI:10.1016/j.egyr.2020.09.024

[3] Li, Xian \&amp; Lin, Alexander \&amp; Young, Chin-Huai\&amp; Dai, Yanjun\&amp; Wang, Chi-Hwa, 2019 \&quot;Energetic and economic evaluation of hybrid solar energy systems in a residential net-zero energy building,\&quot; Applied Energy, Elsevier, vol. 254(C).

[4] Wu, Wei \&amp; Skye, Harrison M. \&amp;Domanski, Piotr A., 2018. \&quot;Selecting HVAC systems to achieve comfortable and cost-effective residential net-zero energy buildings,\&quot; Applied Energy, Elsevier, vol. 212(C), pages 577-591.

[5] G. Davis, Steven J \&amp; Lewis, Nathan S. \&amp;Shaner, Matthew \&amp; Aggarwal, Sonia \&amp;Arent, Doug \&amp; Azevedo, Inês\&amp; Benson, Sally \&amp; Bradley, Thomas \&amp; Brouwer, Jack \&amp; Chiang, Yet-Ming \&amp; Clack, Christopher T.M. \&amp; Co, 2018. \&quot;Net-Zero Emissions Energy Systems,\&quot; Institute of Transportation Studies, Working Paper Series qt7qv6q35r, Institute of Transportation Studies, UC Davis.
[6] Chae, Young Tae \&amp; Kim, Jeehwan\&amp; Park, Hongsik\&amp; Shin, Byungha, 2014. \&quot;Building energy performance evaluation of building integrated photovoltaic (BIPV) window with semi-transparent solar cells,\&quot; Applied Energy, Elsevier, vol. 129(C), pages 217-227.

[7] Deng, S. \&amp; Wang, R.Z. \&amp; Dai, Y.J., 2014. \&quot;How to evaluate performance of net zero energy building - A literature research,\&quot; Energy, Elsevier, vol. 71(C), pages 1-16.

[8] Mohamed, Ayman \&amp; Hasan, Ala \&amp;Sirén, Kai, 2014. \&quot;Fulfillment of net-zero energy building (NZEB) with four metrics in a single family house with different heating alternatives,\&quot; Applied Energy, Elsevier, vol. 114(C), pages 385-399.

[9] C. John Edward Morrissey, Ralph E. Horne "Life cycle cost implications of energy efficiency measures in new residential buildings", April 2011, Energy and Buildings 43(4):915-924.

[10] Li, Danny H.W. \&amp; Yang, Liu \&amp; Lam, Joseph C., 2013. \&quot;Zero energy buildings and sustainable development implications A review,\&quot; Energy, Elsevier, vol. 54(C), pages 1-10

[11] Petros J. Axaopoulos, Emmanouil D. Fylladitakis "Performance and economic evaluation of a hybrid Photovoltaic/Thermal solar system for residential applications" July 2013,Energy and Buildings 65. 